\title{
Catalytic Efficiency of Basidiomycete Laccases: Redox Potential versus Substrate-Binding Pocket Structure
}

\author{
Olga A. Glazunova ${ }^{1, *(1)}$, Nikita A. Trushkin ${ }^{2}$, Konstantin V. Moiseenko ${ }^{1}$, Ivan S. Filimonov ${ }^{3}$ \\ and Tatyana V. Fedorova ${ }^{1}$ \\ 1 A. N. Bach Institute of Biochemistry, Research Center of Biotechnology, Russian Academy of Sciences, \\ Leninsky Ave. 33/2, 119071 Moscow, Russia; mr.moiseenko@gmail.com (K.V.M.); \\ fedorova_tv@mail.ru (T.V.F.) \\ 2 Faculty of Bioengineering and Bioinformatics, Moscow State University, 119992 Moscow, Russia; \\ hydrodiction@gmail.com \\ 3 All-Russian Research Institute for Optophysical Measurements (VNIIOFI), Ozernaya 46, \\ 119361 Moscow, Russia; filimonov@vniiofi.ru \\ * Correspondence: helga758@yandex.ru; Tel.: +7-(495)-954-4477
}

Received: 15 March 2018; Accepted: 2 April 2018; Published: 9 April 2018

\begin{abstract}
Laccases are copper-containing oxidases that catalyze a one-electron abstraction from various phenolic and non-phenolic compounds with concomitant reduction of molecular oxygen to water. It is well-known that laccases from various sources have different substrate specificities, but it is not completely clear what exactly provides these differences. The purpose of this work was to study the features of the substrate specificity of four laccases from basidiomycete fungi Trametes hirsuta, Coriolopsis caperata, Antrodiella faginea, and Steccherinum murashkinskyi, which have different redox potentials of the T1 copper center and a different structure of substrate-binding pockets. Enzyme activity toward 20 monophenolic substances and 4 phenolic dyes was measured spectrophotometrically. The kinetic parameters of oxidation of four lignans and lignan-like substrates were determined by monitoring of the oxygen consumption. For the oxidation of the high redox potential $(>700 \mathrm{mV})$ monophenolic substrates and almost all large substrates, such as phenolic dyes and lignans, the redox potential difference between the enzyme and the substrate $(\Delta E)$ played the defining role. For the low redox potential monophenolic substrates, $\Delta E$ did not directly influence the laccase activity. Also, in the special cases, the structure of the large substrates, such as dyes and lignans, as well as some structural features of the laccases (flexibility of the substrate-binding pocket loops and some amino acid residues in the key positions) affected the resulting catalytic efficiency.
\end{abstract}

Keywords: laccase; substrate specificity; redox potential; substrate-binding-pocket; dilignan

\section{Introduction}

Laccases (benzene diol:dioxygen oxidoreductases; EC 1.10.3.2) are copper-containing oxidases that catalyze a one-electron abstraction from various phenolic and non-phenolic compounds with concomitant reduction of molecular oxygen to water. Laccases can be used in wood, pulp and paper, textile, and food industries [1] as well as soil bioremediation and sewage treatment $[2,3]$.

One of the main distinguishing features of laccases is their ability to oxidize a very wide range of compounds. Typical substrates of laccases are polyphenols, substituted phenols, and aromatic diamines. It is well-known that laccases from various sources have different substrate specificities, but it is not completely clear what exactly provides these differences $[4,5]$. For a long time, it was believed that the catalytic efficiency of substrate oxidation by laccases correlates with a redox potential difference between the substrate and the enzyme T1 copper center [6]. However, at the present moment 
this view is widely challenged by different studies [7]. It seems that the catalytic efficiency of laccases depends not only on the redox potential difference but also on the steric features, such as the substrate shape and the laccase substrate-binding pocket architecture [8,9].

Previously, we isolated and partially characterized four laccases from four different white-rot basidiomycetes: Trametes hirsuta [10], Coriolopsis caperata [11], Steccherinum murashkinskyi, and Antrodiella faginea [12]. The laccases isolated from T. hirsuta and C. caperata have high redox potentials of $780 \mathrm{mV}$ each, while the laccases from S. murashkinskyi and A. faginea possess middle redox potentials of 650 and $620 \mathrm{mV}$, respectively. For all these laccases, the corresponding three-dimensional (3D) structures were experimentally determined $[11,13,14]$ and deposited in the Protein Data Bank with the following entry numbers: 3FPX for T. hirsuta laccase, $4 \mathrm{JHV}$ for $C$. caperata laccase, $5 \mathrm{E} 9 \mathrm{~N}$ for S. murashkinskyi laccase, and 5EHF for A. faginea laccase. All these laccases have a different structure of the loops forming their substrate-binding pockets.

The purpose of this work was to study the features of the substrate specificity of four laccases from T. hirsuta, C. caperata, A. faginea, and S. murashkinskyi, which have different redox potentials of the $\mathrm{T} 1$ copper center and a different structure of the substrate-binding pockets. Obtained results are discussed in terms of the interplay between substrate/enzyme redox potentials and steric interactions.

\section{Results and Discussion}

\subsection{Substrate Specificities of Laccases toward Monophenolic Compounds and Phenolic Dyes}

Four different laccases from basidiomycetes, T. hirsuta (ThL), C. caperata (CcL), S. murashkinskyi (SmL), and A. faginea (AfL), were screened for their ability to oxidize 20 simple monophenolic compounds and 4 phenolic dyes. All chosen compounds form a representative set concerning different structural patterns observed in typical laccase substrates (Figure 1). All four studied laccases can be divided into two groups according to their T1 center redox potentials: ThL $(E=780 \mathrm{mV})$ and CcL $(E=780 \mathrm{mV})$ are high redox potential laccases and $\mathrm{SmL}(E=650 \mathrm{mV})$ and $\mathrm{AfL}(E=620 \mathrm{mV})$ are middle redox potential laccases.

The data regarding activities of laccases toward different substrates are presented in Figure 1. To highlight overall patterns in the oxidation of substrates by all studied laccases, the log-transformed activity values are presented (Figure 1 upper panel). To facilitate the comparison among different laccases, the standardization (Z-scores) of activities was performed (Figure 1 lower panel). Additional information regarding the laccase activity is shown in Table S1.

For all studied laccases, several common tendencies regarding their ability to oxidize different substrates can be observed. Among the cinnamic acid derivatives, the oxidation rates decreased in the series sinapic acid $\left(\mathrm{R}_{2}=\mathrm{OH}, \mathrm{R}_{1,3}=\mathrm{OCH}_{3}\right)>$ ferulic acid $\left(\mathrm{R}_{1}=\mathrm{OCH}_{3}, \mathrm{R}_{2}=\mathrm{OH}, \mathrm{R}_{3}=\mathrm{H}\right)>$ caffeic acid $\left(\mathrm{R}_{1,2}=\mathrm{OH}, \mathrm{R}_{3}=\mathrm{H}\right)>$ isomers of coumaric acid $\left(\mathrm{R}_{2}=\mathrm{OH}, \mathrm{R}_{1,3}=\mathrm{H}\right)$. Among the benzoic acid derivatives, the oxidation rates decreased in the series gallic acid $\left(\mathrm{R}_{1,2,3}=\mathrm{OH}\right)>$ syringic acid $\left(\mathrm{R}_{2}=\mathrm{OH}\right.$, $\left.\mathrm{R}_{1,3}=\mathrm{OCH}_{3}\right)>$ 3,4-dihydroxybenzoic acid $\left(\mathrm{R}_{1,2}=\mathrm{OH}, \mathrm{R}_{3}=\mathrm{H}\right)>$ vanillic acid $\left(\mathrm{R}_{1}=\mathrm{OCH}_{3}, \mathrm{R}_{2}=\mathrm{OH}\right.$, $\left.\mathrm{R}_{3}=\mathrm{H}\right)$. The oxidation rate of the aromatic aldehyde vanillin was lower than that of the vanillic acid.

In general, the benzoic acid derivatives were oxidized at a lower rate than the cinnamic acid derivatives with the same substituents. It is interesting to note that for the benzoic acid derivatives the methoxy substituent showed less influence on the oxidation rates than the hydroxy substituent, whereas for the cinnamic acid derivatives the opposite trend was observed.

In the case of phenol derivatives, the hydroxy substituent in the ortho-position (catechol, $\mathrm{R}_{1}=\mathrm{OH}$, $\mathrm{R}_{2,3,4,5}=\mathrm{H}$ ) was more favorable than the methoxy substituent in the ortho-position (guaiacol, $\mathrm{R}_{1}=\mathrm{OCH}_{3}, \mathrm{R}_{2,3,4,5}=\mathrm{H}$ ) and the hydroxy substituent in the para-position (hydroquinone, $\mathrm{R}_{3}=\mathrm{OH}$, $\mathrm{R}_{1,2,4,5}=\mathrm{H}$ ). The second methoxy substituent in the ortho-position (2,6-dimethoxyphenol, $\mathrm{R}_{1,5}=\mathrm{OCH}_{3}$, $\mathrm{R}_{2,3,4}=\mathrm{H}$ ) did not lead to an increase in the activity. The presence of methyl substituent simultaneously with the hydroxy substituent in the orcinol $\left(\mathrm{R}_{2}=\mathrm{OH}, \mathrm{R}_{4}=\mathrm{CH}_{3}, \mathrm{R}_{1,3,5}=\mathrm{H}\right)$ significantly reduced the 
positive effect of hydroxy substituent, which resulted in the lowest oxidation rate of the orcinol among all phenol derivatives.

All the laccases oxidized the aromatic compounds with the amino group (2,5-xylidine and 2-amino-4-methoxybenzoic acid) at a much lower rate compared to most compounds with the hydroxy group. The same tendency as for the simple monophenolic compounds was observed for the phenolic dyes. All laccases oxidize congo red and indigo carmine containing an amino group and a nitrogen in the indole ring slower than bromocresol green and phenol red containing hydroxy groups in the benzene rings.

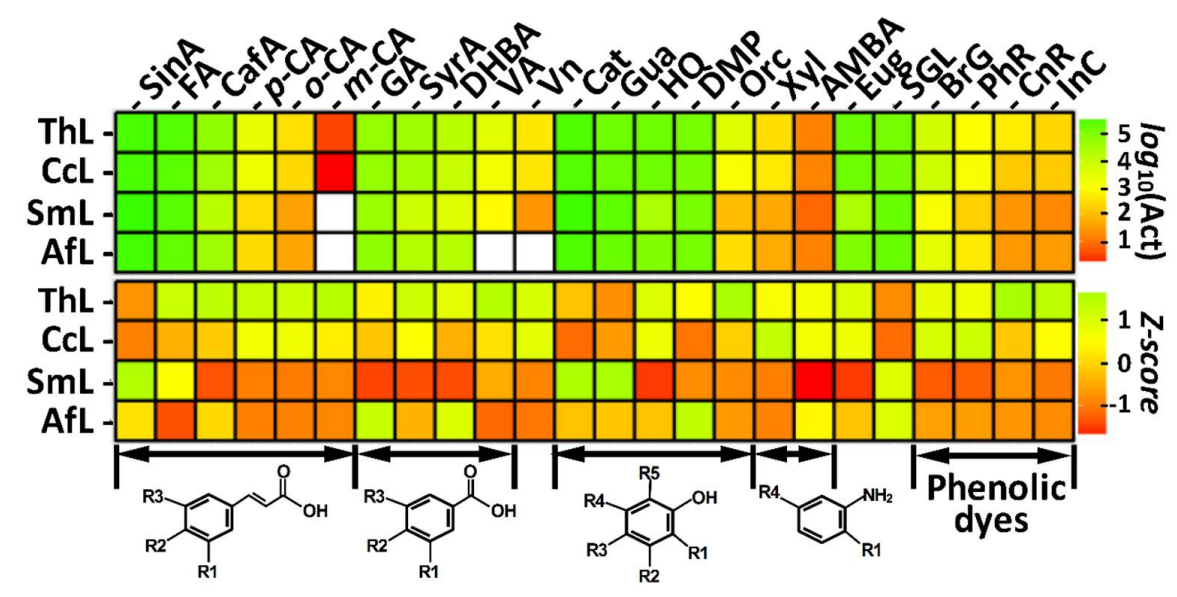

Figure 1. Laccase activities toward different phenolic substrates. The following abbreviations are used: $\operatorname{Sin} \mathrm{A}=$ synapic acid, $\mathrm{FA}=$ ferulic acid, CafA = caffeic acid, $p$-CA = $p$-coumaric acid, $o-\mathrm{CA}=o$-coumaric acid, $m$-CA = m-coumaric acid, GA = gallic acid, SyrA = syringic acid, DHBA = 3,4-dihydroxybenzoic acid, $\mathrm{VA}=$ vanillic acid, $\mathrm{Vn}=$ vanillin, Cat $=$ catechol, Gua = guaiacol, $\mathrm{HQ}=$ hydroquinone, $\mathrm{DMP}=$ 2,6-dimethoxyphenol, Orc = orcinol, $\mathrm{Xyl}=$ 2,5-xylidine, AMBA = 2-amino-4-methoxybenzoic acid, Eug = eugenol, $\mathrm{SGL}=$ syringaldazine, $\mathrm{BrG}=$ bromocresol green, $\mathrm{PhR}=$ phenol red, $\mathrm{CnR}=$ congo red , and $\mathrm{InC}=$ indigo carmine, $\mathrm{ThL}=$ Trametes hirsuta laccase, $\mathrm{CcL}=$ Coriolopsis caperata laccase, $\mathrm{AfL}=$ Antrodiella faginea laccase, and $\mathrm{SmL}=$ Steccherinum murashkinskyi laccase. The white cells on the upper panel represent points where no activity was detected. The Z-scores were obtained by standardization of the original activities for each substrate (table column) separately. The general patterns in the substrate structures are described/depicted under the corresponding entries and the details are described in the main text.

It is worth noting that although all laccases considerably more slowly oxidized compounds with redox potentials above $700 \mathrm{mV}$ (e.g., coumaric acids, vanillic acid, vanillin, 2,5-xylidine [15-17]), the relationship between the rate of the oxidation and the redox potential of the substrates was not so apparent for compounds with lower redox potentials. For example, caffeic acid, which has a lower potential than sinapic acid and ferulic acid [15], was oxidized less efficiently by all laccases. Moreover, in the case of the phenolic dyes, indigo carmine, which has a lower potential than congo red $[18,19]$, was the worst oxidizable substrate for all laccases.

In addition to the fact that the higher rate of substrate oxidation cannot be fully attributed to the lower substrate redox potential, the higher redox potential of laccase does not always guarantee more efficient substrate oxidation. For such substrates as syringaldazine, sinapic acid, and guaiacol, the middle redox potential SmL and AfL showed a significantly higher oxidation rate compared to the high redox potential ThL and CcL. Nevertheless, in the case of the substrates with a redox potential higher than $700 \mathrm{mV}$, the difference between the high redox potential and the middle redox potential laccases became more obvious. The high redox potential laccases (ThL and CcL) oxidized such high redox potential substrates as coumaric acid isomers, vanillic acid, vanillin, and 2,5-xylidine with a higher rate. 
It is interesting that in the case of the phenolic dyes, clearer separation in the oxidation rates among studied laccases was observed. ThL and CCL oxidized all four dyes much more efficiently than AfL and SmL. Apparently, in this case the significantly higher redox potentials of ThL and CcL played a crucial role. Similar to our results, Maijala and colleagues have also shown that the high redox potential laccase from $T$. hirsuta oxidizes large phenolic substrates, such as mataresinol and hydroxymataresinol, more efficiently than the middle redox potential laccases from Melanocarpus albomyces and Thielavia arenaria [20]. However, some patterns cannot be explained based on the redox potential differences alone. Despite the lower potential than SmL, AfL exhibited slightly higher activity toward all phenolic dyes except congo red.

\subsection{Kinetics of Oxidation of Lignans by Laccases}

To investigate the oxidation of large phenolic substrates by the studied laccases, four different lignans and lignan-like compounds, including secoisolariciresinol (SECO), mangiferin (MANG), secoisolariciresinol diglucoside (SDG), and etoposide (ETO), were chosen (Figure 2). The chosen lignans have a different number of glycosidic moieties, which make the substrate bulkier, and possess a different flexibility of their carbon backbone due to the presence of different condensed substructures.<smiles>COc1cc(C[C@@H](CO)[C@H](CO)Cc2ccc(O)c(OC)c2)ccc1O</smiles>

A<smiles>COc1cc(CC(CO[C@H]2O[C@H](CO)[C@@H](O)[C@H](O)[C@H]2O)[C@H](CO[C@H]2O[C@H](CO)[C@@H](O)[C@H](O)[C@H]2O)Cc2ccc(O)c(OC)c2)ccc1O</smiles>

C<smiles>O=c1c2cc(O)c(O)cc2oc2cc(O)c(C3O[C@H](CO)[C@@H](O)[C@H](O)[C@H]3O)c(O)c12</smiles>

B

Figure 2. The structures of the lignans and lignan-like substrates. (A) Secoisolariciresinol; (B) mangiferin; (C) secoisolariciresinol diglucoside; (D) etoposide.

The kinetic constants of oxidation of the lignans by all four laccases are presented in Table 1. In terms of the catalytic efficiency $\left(\mathrm{V}_{\max } / \mathrm{K}_{\mathrm{M}}\right)$, the obtained data can be seen as an interplay between two general tendencies. In terms of laccases, the catalytic efficiencies of oxidation were decreased in the series ThL $>\mathrm{CcL}>\mathrm{AfL}>\mathrm{SmL}$ for all substrates. In terms of substrates, the catalytic efficiencies were decreased in the series SECO $>$ ETO $>$ SDG > MANG for all laccases. The exception in both series was the high catalytic efficiency of MANG oxidation by AfL. Glycoside moieties of ETO, SDG, and MANG negatively affected the oxidation efficiency of all laccases except AfL in the case of ETO oxidation. The negative effect of the presence of glucose residues in the substrate molecules on the laccase catalyzed reaction rate for the T. hirsuta laccase was described previously [21]. However, in our data, CcL oxidized SECO and its glycosylated form SDG with approximately the same $\mathrm{V}_{\max }$. 
Table 1. The catalytic parameters of oxidation of the lignans.

\begin{tabular}{|c|c|c|c|c|c|c|c|c|c|c|c|c|}
\hline & \multicolumn{3}{|c|}{ SECO } & \multicolumn{3}{|c|}{ ETO } & \multicolumn{3}{|c|}{ SDG } & \multicolumn{3}{|c|}{ MANG } \\
\hline & $\begin{array}{c}\mathrm{K}_{\mathrm{M}} \\
(\mu \mathrm{M})\end{array}$ & $\begin{array}{c}\mathrm{V}_{\max } \\
\left(\mu \mathrm{M} \cdot \mathrm{s}^{-1}\right)\end{array}$ & $\begin{array}{c}V_{\max } / \mathrm{K} \\
\left(\times 10^{4} \mathrm{~s}^{-1}\right)\end{array}$ & $\begin{array}{c}\mathrm{K}_{\mathrm{M}} \\
(\mu \mathrm{M})\end{array}$ & $\begin{array}{c}\mathrm{V}_{\max } \\
\left(\mu \mathrm{M} \cdot \mathrm{s}^{-1}\right)\end{array}$ & $\begin{array}{c}\mathrm{V}_{\max } / \mathrm{K} \\
\left(\times 10^{4} \mathrm{~s}^{-1}\right)\end{array}$ & $\begin{array}{c}\mathrm{K}_{\mathrm{M}} \\
(\mu \mathrm{M})\end{array}$ & $\begin{array}{c}\mathrm{V}_{\max } \\
\left(\mu \mathrm{M} \cdot \mathrm{s}^{-1}\right)\end{array}$ & $\begin{array}{c}V_{\max } / \mathbf{K} \\
\left(\times 10^{4} s^{-1}\right)\end{array}$ & $\begin{array}{c}\mathrm{K}_{\mathrm{M}} \\
(\mu \mathrm{M})\end{array}$ & $\begin{array}{c}V_{\max } \\
\left(\mu \mathrm{M} \cdot \mathrm{s}^{-1}\right)\end{array}$ & $\begin{array}{c}\mathrm{V}_{\max } / \mathrm{K} \\
\left(\times 10^{4} \mathrm{~s}^{-1}\right)\end{array}$ \\
\hline ThL & $31 \pm 6$ & $1.75 \pm 0.08$ & 565 & $54 \pm 15$ & $1.52 \pm 0.13$ & 282 & $108 \pm 19$ & $1.21 \pm 0.07$ & 112 & $112 \pm 33$ & $0.57 \pm 0.06$ & 51 \\
\hline CcL & $60 \pm 7$ & $1.68 \pm 0.06$ & 280 & $74 \pm 11$ & $1.83 \pm 0.09$ & 247 & $190 \pm 15$ & $1.60 \pm 0.05$ & 84 & $229 \pm 55$ & $0.64 \pm 0.07$ & 28 \\
\hline AfL & $124 \pm 6$ & $2.04 \pm 0.04$ & 165 & $113 \pm 16$ & $1.80 \pm 0.10$ & 160 & $370 \pm 35$ & $1.23 \pm 0.06$ & 33 & $100 \pm 15$ & $1.06 \pm 0.05$ & 106 \\
\hline SmL & $172 \pm 26$ & $1.76 \pm 0.12$ & 102 & $91 \pm 64$ & $0.30 \pm 0.08$ & 33 & $135 \pm 29$ & $0.34 \pm 0.03$ & 25 & - & $<0.05$ & $<10$ \\
\hline
\end{tabular}

$\mathrm{SECO}=$ Secoisolariciresinol, $\mathrm{ETO}=$ etoposide, $\mathrm{SDG}=$ secoisolariciresinol diglucoside, $\mathrm{MANG}=$ mangiferin.

Similar to the experiments with phenolic dyes, the oxidation efficiencies of lignans oxidation can be roughly attributed to the T1 center redox potential of the laccases. Although the differences in the oxidation efficiencies of lignans between the groups of the high and middle redox potential laccases are well-explained by the redox potentials of the laccases, for the explanation of the differences within these groups some other factors must be considered. In our study, ThL, while having the same redox potential as $\mathrm{CcL}$, always demonstrated a higher efficiency of lignan oxidation. Moreover, AfL, while having a slightly lower redox potential than $\mathrm{SmL}$, always oxidized lignans more efficiently. Apparently, the structure of the substrate-binding pockets of laccases must play a substantial role in the described situations.

It is obvious that the influence of a substrate's structure on its oxidation efficiency must be closely linked with the architecture of the laccase's substrate-binding pockets. Among our laccases, three main differences in the substrate-binding pockets can be observed: the size of the pocket, the flexibility of the pocket-forming loops, and the presence of specific residues that can promote better substrate binding (Figure 3 and Table S2).

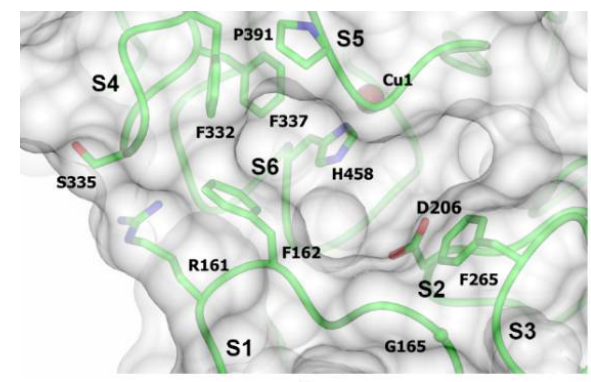

A

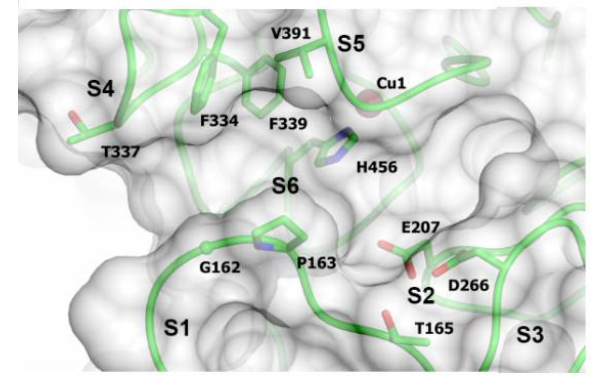

C

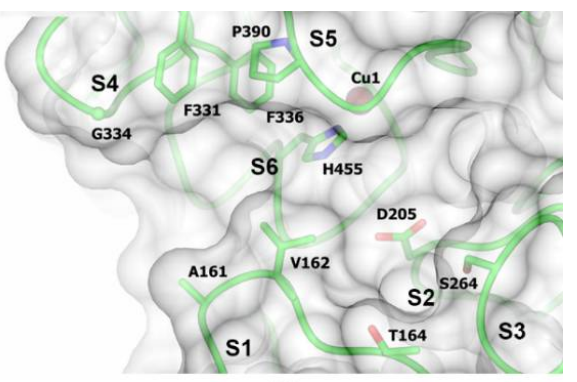

B

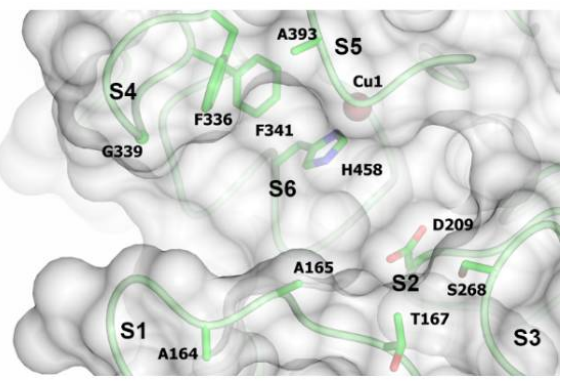

D

Figure 3. The substrate-binding pockets of ThL (A), CcL (B), AfL (C), and SmL (D). The positions of the substrate-binding loops (S1-S5), the amino acid residues delineating the substrate-binding cavity, and the $\mathrm{Cu} 1$ ion are indicated.

While the substrate-binding pocket of ThL is the hydrophobic cavity formed by the loops near the $\mathrm{T} 1$ center, the substrate-binding pockets of $\mathrm{CcL}$, AfL, and SmL lack one of the pocket walls (Figure 3). In ThL, this side wall is formed by the side chains of the residues Phe162 and Arg161. In addition, the Arg161 side chain forms a hydrogen bond with the main chain of the Ser335 residue, which is a part of the loop S4 of the substrate-binding pocket on the opposite side. In CcL, AfL, and SmL, 
Arg161 is substituted with Ala or Gly residues (Figure 3), which cannot form the hydrogen bonds via their side chains. The length of the substrate-binding loops also differs between the laccases (Table S2, Figure 3). In AfL and SmL, compared to ThL and CcL, the loop S1 is longer and the loop S5 is shorter, which result in more spacious substrate-binding pockets. Nevertheless, it seems that a more spacious substrate-binding pocket alone does not positively affect the catalytic efficiency or the affinity of AfL and SmL to lignans.

An analysis of the temperature factors of the residues in the loops of the substrate-binding pockets of laccases showed that the flexibility of the loops increases in the series $\mathrm{ThL}<\mathrm{CcL}<\mathrm{SmL}<\mathrm{AfL}$.

Earlier, Galli and colleagues showed a detrimental effect of some point mutations in the enzyme substrate-binding pocket on the efficiency of oxidation of large substrates by the Trametes versicolor laccase [9]. The substitution of F162A and F265A by Ala residues almost in all cases reduced the oxidation efficiency, presumably due to the decrease of the substrate-binding pocket's hydrophobicity and the loss of the stacking interactions with the substrate. Among the all laccases studied, only ThL contains the phenylalanine residues in these positions (Table S2).

We suppose that the main difference within the groups of the high and middle redox potential laccases is not driven only by the redox potential difference but by the structure of the substrate-binding pockets of laccases. In the case of the high redox potential laccases, the main determinant of the catalytic efficiency seems to be the presence of Phe162 and Phe265 residues in ThL that can promote tighter bonding of the substrate compared to CcL. Regarding the middle redox potential laccases, the flexibility of the substrate-binding pocket loops plays a defining role. More flexible loops in AfL can result in a more advantageous substrate binding compared to SmL.

The exceptionally high catalytic efficiency of MANG oxidation by AfL also can be attributed to the substrate-binding pocket architecture. Unlike SECO, SDG, and ETO, in MANG the hydroxy group oxidized by laccase is attached to a system of three condensed benzene rings that make this part of the substrate extremely stiff and flat. While having a wider substrate-binding pocket than ThL, AfL also has the most flexible loops among all of the studied laccases. Another feature of the AfL substrate-binding pocket is the presence of Glu207 residue instead of Asp residue as in other laccases. The residue in this position is believed to participate in substrate binding [22,23]. The longer side chain of the Glu residue is more accessible to the substrate. These features allow positioning MANG more properly than in other laccases and apparently a more proper positioning of the substrate supersedes the redox potential factor in this particular case.

In summary, a high redox potential and a presence of the hydrophobic phenylalanine residues in the key positions made ThL almost always the most effective laccase for the oxidation of the large substrates. CCL has the same redox potential as ThL, but lacked these phenylalanine residues and so was less effective. In the case of the middle redox potential laccases AfL and SmL, the flexibility of the substrate-binding loops seems to be more important than the slight difference in the T1 copper center redox potentials. Moreover, for such a bulky and rigid substrate as MANG, AfL, despite having the lowest redox potential among all of the studied laccases, was the most efficient.

\section{Materials and Methods}

\subsection{Fungal Strains}

The mycelial cultures of the basidiomycete strains were received from the Collection of the Komarov Botanical Institute, Russian Academy of Sciences (St. Petersburg): Trametes hirsuta (LE-BIN 072), Coriolopsis caperata (LE-BIN 067), Steccherinum murashkinskyi (LE-BIN 1963), and Antrodiella faginea (LE-BIN 1998). The fungal strains were maintained at $4{ }^{\circ} \mathrm{C}$ on slants with a wort-agar medium, prepared by diluting the brewer wort (Northern Brewery, Saint-Petersburg, Russia) with water in a 1:4 $(v / v)$ ratio and adding 2\% agar (Difco Laboratories, Detroit, MI, USA). 


\subsection{Culturing Conditions and Enzyme Purification}

The cultivation was carried out as described in [24] using the glucose-peptone medium of following composition $\left(\mathrm{g} \cdot \mathrm{L}^{-1}\right)$ : glucose $=10.0$, peptone $=3.0, \mathrm{KH}_{2} \mathrm{PO}_{4}=0.6, \mathrm{~K}_{2} \mathrm{HPO}_{4}=0.4$, $\mathrm{ZnSO}_{4} \times 7 \mathrm{H}_{2} \mathrm{O}=0.001, \mathrm{FeSO}_{4} \times 7 \mathrm{H}_{2} \mathrm{O}=0.0005, \mathrm{MnSO}_{4}=0.05, \mathrm{MgSO}_{4} \times 7 \mathrm{H}_{2} \mathrm{O}=0.5, \mathrm{CaCl}_{2}=0.5$. The laccase preparations were isolated from the cultural liquid after submerged cultivation by filtration (Whatman No. 1 filter paper) and purified as described in [11]. Briefly, the purification procedure consisted of two stages of ion-exchange chromatography on DEAE Cellulose and Toyopearl DEAE 650 M (Tosoh, Tokyo, Japan) followed by gel-filtration on a Superdex $75(26 / 60)$ column (GE Healthcare Life Sciences, Chicago, IL, USA). The homogeneity of laccase preparations was confirmed by SDS-PAGE (12.5\% acrylamide) in a Mini-PROTEAN 3 device (Bio-Rad, Hercules, CA, USA) (Figure S1).

\subsection{Biochemical Assays}

All substrates were dissolved to a concentration of $10 \mathrm{mM}$ in $95.6 \%$ ethanol. The reactions were performed at $25^{\circ} \mathrm{C}$. The reaction mixtures contained $1800 \mu \mathrm{L}$ of $0.1 \mathrm{M}$ sodium acetate buffer $\mathrm{pH} 4.5,200 \mu \mathrm{L}$ of the substrate solution, and $10 \mu \mathrm{L}$ of the laccase solution with a concentration of $0.1 \mathrm{mg} \cdot \mathrm{mL}^{-1}$. A UV-Vis scan between $230 \mathrm{~nm}$ and $700 \mathrm{~nm}$ was recorded prior to the enzyme addition and every $70 \mathrm{~s}$ after the enzyme addition for $12 \mathrm{~min}$ in total with a Lambda 35 spectrometer (Perkin Elmer, Waltham, MA, USA). The reaction rates for $p$-coumaric acid $\left(\varepsilon_{290}=15,900 \mathrm{~cm}^{-1} \cdot \mathrm{M}^{-1}\right), o$-coumaric acid $\left(\varepsilon_{315}=6580 \mathrm{~cm}^{-1} \cdot \mathrm{M}^{-1}\right)$, $m$-coumaric acid $\left(\varepsilon_{272}=13,440 \mathrm{~cm}^{-1} \cdot \mathrm{M}^{-1}\right)$, caffeic acid $\left(\varepsilon_{315}=12,930 \mathrm{~cm}^{-1} \cdot \mathrm{M}^{-1}\right), 3,4$-dihydroxybenzoic acid $\left(\varepsilon_{290}=4740 \mathrm{~cm}^{-1} \cdot \mathrm{M}^{-1}\right)$, syringic acid $\left(\varepsilon_{265}=8060 \mathrm{~cm}^{-1} \cdot \mathrm{M}^{-1}\right)$, vanillic acid $\left(\varepsilon_{289}=4580 \mathrm{~cm}^{-1} \cdot \mathrm{M}^{-1}\right)$, hydroquinone $\left(\varepsilon_{289}=2390 \mathrm{~cm}^{-1} \cdot \mathrm{M}^{-1}\right)$, vanillin $\left(\varepsilon_{309}=9750 \mathrm{~cm}^{-1} \cdot \mathrm{M}^{-1}\right)$, 2-amino-4-metoxybenzoic acid $\left(\varepsilon_{318}=3560 \mathrm{~cm}^{-1} \cdot \mathrm{M}^{-1}\right)$, sinapic acid $\left(\varepsilon_{306}=14,640 \mathrm{~cm}^{-1} \cdot \mathrm{M}^{-1}\right)$, and ferulic acid $\left(\varepsilon_{314}=12,940 \mathrm{~cm}^{-1} \cdot \mathrm{M}^{-1}\right)$ were evaluated by the substrate consumption and for orcinol $\left(\varepsilon_{341}=840 \mathrm{~cm}^{-1} \cdot \mathrm{M}^{-1}\right)$, eugenol $\left(\varepsilon_{360}=2300 \mathrm{~cm}^{-1} \cdot \mathrm{M}^{-1}\right), \quad 2,5$-xylidine $\left(\varepsilon_{540}=1980 \mathrm{~cm}^{-1} \cdot \mathrm{M}^{-1}\right)$, catechol $\left(\varepsilon_{410}=740 \mathrm{~cm}^{-1} \cdot \mathrm{M}^{-1}\right)$, 2,6-dimetoxyphenol $\left(\varepsilon_{470}=35,645 \mathrm{~cm}^{-1} \cdot \mathrm{M}^{-1}\right)$, guaiacol $\left(\varepsilon_{464}=6590 \mathrm{~cm}^{-1} \cdot \mathrm{M}^{-1}\right)$, syringaldazine $\left(\varepsilon_{520}=65,000 \mathrm{~cm}^{-1} \cdot \mathrm{M}^{-1}\right)$, and gallic acid $\left(\varepsilon_{386}=4610 \mathrm{~cm}^{-1} \cdot \mathrm{M}^{-1}\right)$ by product formation. One unit of activity was defined as $\mu \mathrm{M}$ of substrate (product) consumed (formed) per min by $1 \mu \mathrm{g} \cdot \mathrm{L}^{-1}$ of enzyme.

The kinetic parameters of secoisolariciresinol (SECO), secoisolariciresinol diglucoside (SDG), etoposide (ETO), and mangiferin (MANG) oxidation were determined by monitoring of the oxygen consumption using an MTH-001 potentiostat (Econix-Expert, Moscow, Russia), equipped with a Clark-type electrode. The reactions were performed at $25^{\circ} \mathrm{C}$. SECO, SDG, and ETO were dissolved in ethanol, and MANG in DMSO. The reactions were initiated by addition of $25 \mu \mathrm{L}$ of the laccase solution with a concentration of $0.1 \mathrm{mg} \cdot \mathrm{mL}^{-1}$ to $2000 \mu \mathrm{L}$ of the substrate solution in $0.1 \mathrm{M}$ citrate-phosphate buffer $\mathrm{pH}$ 4.5. The substrate concentrations were 10-1000 $\mu \mathrm{M}$ for SECO, SDG, and MANG and 5-500 $\mu \mathrm{M}$ for ETO. Kinetic parameters were calculated by non-linear fitting using the Origin-Lab program (Northampton, MA, USA).

All substrates were purchased from Sigma-Aldrich (St. Louis, MO, USA).

\subsection{Enzyme Structure Analysis}

The flexibility of the loops forming the substrate-binding pockets was estimated in terms of B-factors using the method described in [25]. The B-factors of the Ca atoms were normalized as Z-scores and the mean B-factor for each loop was calculated. The structural pictures were constructed with CCP4MG [26].

\section{Conclusions}

The high redox potential laccases showed higher activity toward the high redox potential $(>700 \mathrm{mV})$ monophenolic substrates. However, for the low redox potential monophenolic substrates, the redox potential difference between the enzyme and the substrate did not directly influence the laccase activity. 
For the oxidation of the large substrates, such as phenolic dyes and lignans, the redox potential difference between the enzyme and substrate played the defining role. High redox potential laccases almost always oxidized large substrates more efficiently that the middle potential laccases. Nevertheless, the redox potential alone cannot explain the different oxidation efficiency of laccases with similar redox potential. Hence, we propose that the structure of the substrate as well as some structural features of the laccase's substrate-binding pocket affect the resulting catalytic efficiency.

The most effective was ThL, which has a high redox potential and two Phe residues at the key positions in the substrate-binding pocket. At the same time, AfL showed higher efficiency compared to $\mathrm{SmL}$, which has a greater redox potential but more rigid substrate-binding loops. Moreover, in the case of such a bulky and rigid substrate as MANG, AfL, which has the most flexible substrate-binding loops, was the most efficient laccase.

Supplementary Materials: The following are available online at http:/ /www.mdpi.com/2073-4344/8/4/152/s1, Table S1: Specific activity of laccases, Table S2: ClustalW alignment of the potential laccase substrate-binding region near T1 copper center. Figure S1: SDS-PAAG electrophoresis of purified laccases.

Acknowledgments: This work was supported by the Russian Foundation for Basic Research [grant number 16-34-01355]. The work was carried out using the Shared Use Equipment Center for high precision measuring in photonics (ckp.vniiofi.ru, VNIIOFI).

Author Contributions: O.A.G., I.S.F., and T.V.F. conceived and designed the experiments; O.A.G. and N.A.T. performed the experiments; O.A.G., K.V.M., and I.S.F. analyzed the data; O.A.G. and K.V.M. wrote the paper; T.V.F. supervised the study and revised the manuscript.

Conflicts of Interest: The authors declare no conflicts of interest.

\section{References}

1. Pezzella, C.; Guarino, L.; Piscitelli, A. How to enjoy laccases. Cell. Mol. Life Sci. 2015, 72, 923-940. [CrossRef] [PubMed]

2. Shekher, R.; Sehgal, S.; Kamthania, M.; Kumar, A. Laccase: Microbial Sources, Production, Purification, and Potential Biotechnological Applications. Enzyme Res. 2011, 2011, 1-11. [CrossRef]

3. Rivera-Hoyos, C.M.; Morales-Alvarez, E.D.; Poutou-Pinales, R.A.; Pedroza-Rodriguez, A.M.; Rodriguez-Vazquez, R.; Delgado-Boada, J.M. Fungal laccases. Fungal Biol. Rev. 2013, 27, 67-82. [CrossRef]

4. Reiss, R.; Ihssen, J.; Richter, M.; Eichhorn, E.; Schilling, B.; Thöny-Meyer, L. Laccase versus Laccase-Like Multi-Copper Oxidase: A Comparative Study of Similar Enzymes with Diverse Substrate Spectra. PLoS ONE 2013, 8, e65633. [CrossRef] [PubMed]

5. Baldrian, P. Fungal laccases-Occurrence and properties. FEMS Microbiol. Rev. 2006, 30, 215-242. [CrossRef] [PubMed]

6. $\mathrm{Xu}, \mathrm{F}$. Oxidation of phenols, anilines, and benzenethiols by fungal laccases: Correlation between activity and redox potentials as well as halide inhibition. Biochemistry 1996, 35, 7608-7614. [CrossRef] [PubMed]

7. Frasconi, M.; Favero, G.; Boer, H.; Koivula, A.; Mazzei, F. Kinetic and biochemical properties of high and low redox potential laccases from fungal and plant origin. Biochim. Biophys. Acta 2010, 1804, 899-908. [CrossRef] [PubMed]

8. Tadesse, M.; D'Annibale, A.; Galli, C. An assessment of the relative contributions of redox and steric issues to laccase specificity towards putative substrates. Org. Biomol. Chem. 2008, 6, 868-878. [CrossRef] [PubMed]

9. Galli, C.; Gentili, P.; Jolivalt, C. How is the reactivity of laccase affected by single-point mutations? Engineering laccase for improved activity towards sterically demanding substrates. Appl. Microbiol. Biotechnol. 2011, 91, 123-131. [CrossRef] [PubMed]

10. Rebrikov, D.V.; Stepanova, E.V.; Koroleva, O.V.; Budarina, Z.I.; Zakharova, M.V.; Yurkova, T.V.; Solonin, A.S.; Belova, O.V.; Pozhidaeva, Z.A.; et al. Laccase of the lignolytic fungus Trametes hirsuta: Purification and characterization of the enzyme and cloning and primary structure of the gene. Appl. Biochem. Microbiol. 2007, 43, 365. [CrossRef]

11. Glazunova, O.A.; Polyakov, K.M.; Fedorova, T.V.; Dorovatovskii, P.V.; Koroleva, O.V. Elucidation of the crystal structure of Coriolopsis caperata laccase: Restoration of the structure and activity of the native enzyme from the T2-depleted form by copper ions. Acta Crystallogr. Sect. D Biol. Crystallogr. 2015, 71, 854-861. [CrossRef] [PubMed] 
12. Glazunova, O.A.; Fedorova, T.V.; Maloshenok, L.G.; Shakhova, N.V.; Polyakov, K.M.; Koroleva, O.V. Purification and characterization of novel laccase from basidiomycete Antrodiella faginea 1998. FEBS J. 2013, 280, 124.

13. Polyakov, K.M.; Fedorova, T.V.; Stepanova, E.V.; Cherkashin, E.A.; Kurzeev, S.A.; Strokopytov, B.V.; Lamzin, V.S.; Koroleva, O.V. Structure of native laccase from Trametes hirsuta at 1.8 A resolution. Acta Crystallogr. Sect. D Biol. Crystallogr. 2009, 65, 611-617. [CrossRef] [PubMed]

14. Glazunova, O.A.; Polyakov, K.M.; Moiseenko, K.V.; Kurzeev, S.A.; Fedorova, T.V. Structure-function study of two new middle-redox potential laccases from basidiomycetes Antrodiella faginea and Steccherinum murashkinskyi. 2018, in press.

15. González, M.D.; Vidal, T.; Tzanov, T. Electrochemical study of phenolic compounds as enhancers in laccase-catalyzed oxidative reactions. Electroanalysis 2009, 21, 2249-2257. [CrossRef]

16. Yakovleva, K.E.; Kurzeev, S.A.; Stepanova, E.V.; Fedorova, T.V.; Kuznetsov, B.A.; Koroleva, O.V. Characterization of Plant Phenolic Compounds by Cyclic Voltammetry. Prikl. Biokhim. Mikrobiol. 2007, 43, 730-739. [CrossRef]

17. Suatoni, J.C.; Snyder, R.E.; Clark, R.O. Voltammetric Studies of Phenol and Aniline Ring Substitution. Anal. Chem. 1961, 33, 1894-1897. [CrossRef]

18. Meyer, H.W.; Treadwell, W.D. Über die Redoxpotentiale von einigen Polyoxyanthrachinonen und Küpenfarbstoffen. Helv. Chim. Acta 1952, 35, 1444-1460. [CrossRef]

19. Sun, J.; Hu, Y.Y.; Hou, B. Electrochemical characteriztion of the bioanode during simultaneous azo dye decolorization and bioelectricity generation in an air-cathode single chambered microbial fuel cell. Electrochim. Acta 2011, 56, 6874-6879. [CrossRef]

20. Maijala, P.; Mattinen, M.-L.; Nousiainen, P.; Kontro, J.; Asikkala, J.; Sipilä, J.; Viikari, L. Action of fungal laccases on lignin model compounds in organic solvents. J. Mol. Catal. B Enzym. 2012, 76, 59-67. [CrossRef]

21. Mattinen, M.L.; Struijs, K.; Suortti, T.; Mattila, I.; Kruus, K.; Willför, S.; Tamminen, T.; Vincken, J.P. Modification of lignans by Trametes hirsuta laccase. BioResources 2009, 4, 482-496.

22. Bertrand, T.; Jolivalt, C.; Briozzo, P.; Caminade, E.; Joly, N.; Madzak, C.; Mougin, C. Crystal structure of a four-copper laccase complexed with an arylamine: Insights into substrate recognition and correlation with kinetics. Biochemistry 2002, 41, 7325-7333. [CrossRef] [PubMed]

23. Kallio, J.; Auer, S.; Jänis, J.; Andberg, M.; Kruus, K.; Rouvinen, J.; Koivula, A.; Hakulinen, N. Structure-function studies of a Melanocarpus albomyces laccase suggest a pathway for oxidation of phenolic compounds. J. Mol. Biol. 2009, 392, 895-909. [CrossRef] [PubMed]

24. Fedorova, T.V.; Shakhova, N.V.; Klein, O.I.; Glazunova, O.A.; Maloshenok, L.G.; Kulikova, N.A.; Psurtseva, N.V.; Koroleva, O.V. Comparative analysis of the ligninolytic potential of basidiomycetes belonging to different taxonomic and ecological groups. Appl. Biochem. Microbiol. 2013, 49, 570-580. [CrossRef]

25. Parthasarathy, S.; Murthy, M.R.N. Analysis of temperature factor distribution in high-resolution protein structures. Protein Sci. 1997, 6, 2561-2567. [CrossRef] [PubMed]

26. McNicholas, S.; Potterton, E.; Wilson, K.S.; Noble, M.E.M. Presenting your structures: The CCP4mg molecular-graphics software. Acta Crystallogr. Sect. D Biol. Crystallogr. 2011, 67, 386-394. [CrossRef] [PubMed]

(C) 2018 by the authors. Licensee MDPI, Basel, Switzerland. This article is an open access article distributed under the terms and conditions of the Creative Commons Attribution (CC BY) license (http://creativecommons.org/licenses/by/4.0/). 